\title{
DOES SIMILAR WHOLE BODY COOLING INDUCE GENDER-SPECIFIC ATTENTION STABILITY DETERIORATION?
}

\author{
Rima Solianik, Albertas Skurvydas, Marius Brazaitis \\ Lithuanian Sports University, Kaunas, Lithuania
}

\begin{abstract}
Background. There is evidence of greater whole body cooling induced unpredictable task switching and memory deterioration in men than in women; however, it is not known how whole body cooling affects attention stability. This study aimed at identifying if there are any gender-specific differences in the effect of cold water immersioninduced stress on attention stability.

Methods. Thirteen men and thirteen women were exposed to acute cold stress by immersion in $14^{\circ} \mathrm{C}$ water until rectal temperature reached $35.5^{\circ} \mathrm{C}$ or for a maximum of $170 \mathrm{~min}$. Thermoregulatory response (i.e. changes of body temperature and metabolic heat production) and attention stability response (i.e. Schulte table (less cognitively demanding task) and Schulte-Gorbov table (more cognitively demanding task)) were monitored.

Results. During cold stress, body temperature variables decreased $(p<.05)$ and did not differ between genders. Metabolic heat production was greater $(p<.05)$ in men than in women. Body cooling significantly increased $(p<.05)$ the duration of Schulte table performance for both genders, whereas an increase $(p<.05)$ of the duration of Schulte-Gorbov table performance was observed only in men.

Conclusion. This is the first study to find the evidence supporting the idea of gender-specific and task-dependent attention stability response after whole body cooling. Whole body cooling induced stress had similar influence on simple attention stability task in men and women, whereas more complex task was adversely affected only in men. This greater men's decrement of complex task performance can be associated with their greater catecholaminesinduced metabolic heat production.
\end{abstract}

Keywords: men, women, cognitive performance, metabolic heat production, shivering.

\section{INTRODUCTION}

I $\mathrm{t}$ is well established that exposure to a whole body (peripheral and central) cooling induced stress impairs cognitive performance and shows a dose-response relationship between decreased cognitive performance and core body temperature (Palinkas, 2001). The adverse effect of marked core cooling as a decreased vigilance, attention and memory can be observed (Brazaitis et al., 2014b; Coleshaw, van Someren, Wolff, Davis, \& Keatinge, 1983; Giesbrecht, Arnett, Vela, \& Bristow, 1993; Lockhart, Jamieson, Steinman, \& Giesbrecht, 2005; Mäkinen et al., 2006; Palinkas, 2001; Solianik, Skurvydas, Vitkauskiene, \&
Brazaitis, 2014b). Furthermore, it is suggested that cold-induced cognitive perturbations are taskdependent (Giesbrecht et al. 1993; Mäkinen, 2007). It seems that especially simple cognitive tasks are adversely affected by cold, while more complex tasks performance may even improve upon shortterm exposure (Giesbrecht et al., 1993; Mäkinen, 2007) and decline following central body cooling of $2-4^{\circ} \mathrm{C}$ (Giesbrecht et al., 1993).

A recent study showed that during whole body cooling strategies of physiological adjustments to cold stress differ between men and women, i.e. men are more reliant on metabolic strategy, including 
shivering thermogenesis (Solianik et al., 2014b). It is well established that metabolic heat production (MHP) and shivering is aided by catecholamines (Banet, Hensel, \& Liebermann, 1978; Maggs, Gallen, Fone, \& Macdonald, 1994), whose response is greater during cold exposure in men than in women (Solianik et al., 2014b; Wagner, Horvath, Kitagawa, \& Bolduan, 1987). It is suggested that cold-induced catecholamines dysregulation reduces cognitive function; particularly, catecholamines are important for tests involving complex attentional functions (Hyafil, Summerfield, \& Koechlin, 2009). According to previously mentioned MHP and shivering differences between men and women, we hypothesized that men would have greater cognitive function alteration then women, especially during more complex task performance.

Shansky and Lipps (2013) stated that most research is conducted in men, and thus our general understanding of the effects of stress on cognitive function is in the context of the men's brain. There is evidence of greater whole body cooling induced unpredictable task switching and memory deterioration in men than in women (Solianik, Skurvydas, Mickevičienè, \& Brazaitis, 2014a), however it is not known how whole body cooling affects attention stability in men and women. Thus, the aim of the research was to identify if there are any gender-specific differences in the effect of cold water immersion-induced stress on attention stability.

\section{METHODS}

Participants. The criteria for inclusion were: age 18-25 years; no excessive sport activities, i.e. $<3$ times per week; no involvement in any temperature-manipulation program or extreme temperature exposure for $\geq 3$ months; non-smokers; and no medications (including oral contraceptives) that could affect natural thermoregulation. Participants were excluded from the study if they had Raynaud's syndrome, asthma, neurological pathology, or conditions that could be worsened by exposure to cold water. Finally, 26 volunteers (13 men and 13 women) met the inclusion criteria and agreed to participate in this study. Their physical characteristics are presented in Table 1. Written informed consent was obtained from all participants after the explanation of all details of the experimental procedures and the associated discomforts and risks. All procedures were conducted according to the guidelines of the Declaration of Helsinki. The Kaunas Regional Research Committee approved this study (2011-10-12 No. BE-2-41). Participants were in self-reported good health, as confirmed by medical history and physical examination. Women were in the follicular phase of their menstrual cycle.

Experimental design. Before the experimental trial, the participants attended a familiarization session. On arrival at the laboratory, anthropometric variables were measured, and the participants were introduced to the experimental procedures for cognitive testing. Each participant performed all cognitive tests for three days continuously. The participants were instructed to refrain from consuming any food for at least $12 \mathrm{~h}$ and alcohol, heavy exercise, and caffeine for at least 24 hours before the experiment, and they were instructed to sleep at least 8 hours the night before the experiment.

One week after the familiarization trial, the participants attended an experimental session. To control for circadian fluctuations in body temperature, the experimental trial began at 7.00. On arrival at the laboratory, the participant was asked to lie down in a semirecumbent position for $30 \mathrm{~min}$ at an ambient temperature of $22^{\circ} \mathrm{C}$ and $60 \%$ relative humidity. Resting pulmonary gas exchange was recorded during the last $20 \mathrm{~min}$. After body temperature stabilization, control measurements of skin $\left(\mathrm{T}_{\mathrm{SK}}\right)$ and rectal $\left(\mathrm{T}_{\mathrm{RE}}\right)$ temperature were made. The participant was then seated at a table, and cognitive testing was performed. After the cognitive testing, the participant began the cooling protocol. Participants were immersed in a semirecumbent position up to the level of the manubrium in the $14^{\circ} \mathrm{C}$ water bath. During cooling, every $20 \mathrm{~min}$, the participant was asked to step out of the bath and rest for $10 \mathrm{~min}$ in the room environment, and then to return to the water bath for the next $20 \mathrm{~min}$ of immersion. This process continued until the $\mathrm{T}_{\mathrm{RE}}$ decreased to $35.5^{\circ} \mathrm{C}$ or until $170 \mathrm{~min}$ in total, at which time the cooling ended regardless of the $T_{R E}$. The exposure time until the $T_{R E}$ was achieved was recorded. $T_{R E}$ was recorded every 5 min throughout the cooling experiment. Pulmonary gas exchange was recorded only during each $20 \mathrm{~min}$ water immersion. Immediately after the experimental cooling, the participant was towel dried, the $\mathrm{T}_{\mathrm{SK}}$ and $\mathrm{T}_{\mathrm{RE}}$ were measured, and cognitive tests were performed.

\section{Experimental measurements}

Anthropometric measurements. The participant's weight (in kg) (TBF-300 body composition scale; Tanita, UK Ltd., West Drayton, UK) and height (in $\mathrm{cm}$ ) were estimated, and body mass index (in $\mathrm{kg} / \mathrm{m}^{2}$ ) was calculated during 
the familiarization trial. The participant's body surface area (BSA) (in $\mathrm{m}^{2}$ ) was estimated using the following best-fit equations: $\mathrm{BSA}=128.1 \times$ weight $^{0.44} \times$ height $^{0.60}$ for men and BSA $=147.4 \times$ weight $^{0.47} \times$ height $^{0.55}$ for women (Tikuisis, Jacobs, Moroz, Vallerand, \& Martineau, 2000).

Temperature recording. The $\mathrm{T}_{\mathrm{RE}}$ (in ${ }^{\circ} \mathrm{C}$ ) was monitored with a thermocouple (Rectal Probe, Ellab, Hvidovre, Denmark) inserted to a minimum of $12 \mathrm{~cm}$ past the anal sphincter. Back, thigh, and forearm skin temperatures were monitored by surface thermistors (DM852, Ellab, Hvidovre, Denmark). The mean skin temperature $\left(\mathrm{T}_{\mathrm{SK}}\right)$ and body temperature $\left(\mathrm{T}_{\mathrm{B}}\right)\left(\right.$ in $\left.{ }^{\circ} \mathrm{C}\right)$ were estimated by the following equations: $\mathrm{T}_{\mathrm{SK}}=0.5_{\mathrm{Back}}+0.36_{\text {Thigh }}+$ $0.14_{\text {Forearm }}$ (Burton, 1935) and $\mathrm{T}_{\mathrm{B}}=0.65 \mathrm{~T}_{\mathrm{RE}}+$ $0.35 \mathrm{~T}_{\mathrm{SK}}$ (Mermier, Schneider, Gurney, Weingart, \& Wilmerding, 2006), respectively. The $T_{R E}$ and $T_{S K}$ gradient $\left(\mathrm{T}_{\mathrm{RE}}-\mathrm{T}_{\mathrm{SK}}\right)$, as a measure of insulation, were also calculated.

Pulmonary gas exchange measurement. A mobile spirometry system (Oxycon Mobile, Jaeger/ VIASYS Healthcare, Hoechberg, Germany) was used to measure pulmonary gas exchange at rest and during cold-water immersion. This system uses a tightly fitting face mask covering the nose and mouth with a lightweight integrated flow meter (Triple V volume sensor, $45 \mathrm{~g}$ ) with a dead space of $30 \mathrm{ml}$. It monitors oxygen consumption $\left(\mathrm{VO}_{2}\right)$ and carbon dioxide production $\left(\mathrm{VCO}_{2}\right)$ every $5 \mathrm{~s}$ on a breath-by-breath basis. The processing, recording, and battery system comprises two units attached to a belt, which was kept as close as possible to the participant's nose and mouth during immersion. The data were stored on a memory card and PC hardware. Calibration of this instrument was performed before recording according to the manufacturer's instructions. Resting $\mathrm{VO}_{2}$ and $\mathrm{VCO}_{2}$ were calculated as average from the last $20 \mathrm{~min}$ of the baseline recording. Because the total waterimmersion time differed between participants, the mean values for stress $\mathrm{VO}_{2}$ (an index of shivering (Muller et al., 2012)), and $\mathrm{VCO}_{2}$ were calculated as the average during the cold-water immersion sessions. The data collected during the first $5 \mathrm{~min}$ of each $20 \mathrm{~min}$ immersion were not used in any calculations because of reflex hyperventilation caused by cold-water immersion. The MHP was calculated from the respiratory gas exchange measurements of $\mathrm{VO}_{2}$ and the respiratory exchange ratio $\left(\mathrm{RER}=\mathrm{VCO}_{2} / \mathrm{VO}_{2}\right.$ ) according to Péronnet and Massicotte (1991) as follows: $\mathrm{MHP}=(281.65+$ $80.65 \times \mathrm{RER}) \times \mathrm{VO}_{2}$. For comparative purposes,
MHP (in W) and $\mathrm{VO}_{2}$ (in $\mathrm{ml} / \mathrm{min}$ ) were normalized against weight and BSA. Furthermore, the function of shivering was expressed relatively to baseline MHP, where low shivering intensity corresponds to $<2.5$ of baseline MHP, moderate shivering intensity corresponds to $2.5-3.8$ of baseline MHP, and high shivering intensity corresponds to $3.8-5$ of baseline MHP (Haman, 2006).

Measurement of cognitive performance. A programmed cognitive test battery was used to assess attention stability. As reported previously (Berneckè et al., 2012), the reliability of chosen tests was considered acceptable because the intraclass correlations were $R>.90$ and the coefficient of variation for repeated tests was $<4 \%$. All tasks were computer controlled, and the information was presented on the screen of a laptop (HP Compaq 6730b). All tests were performed in a quiet and semi-darkened laboratory with a laptop screen $\sim 40 \mathrm{~cm}$ in front of the participant. The test battery took $\sim 5$ min to perform and included the following tasks in random order.

The Schulte table assesses attention stability and is a validated technique for the estimation of concentration and switching of attention (Gordeev, 2008; Prokopenko et al., 2013). Standard values of full one table completion correspond to $40-45 \mathrm{~s}$ (Prokopenko et al., 2013). In the middle of the screen there appeared a five-by-five square table in which the numbers from 1 to 25 were displayed in random order. Participants had to find and click the mouse button on figures in an increasing order from 1 to 25 without omission. After one table was accomplished, the next table appeared on the screen. Participants had to accomplish 5 tables as fast as possible and the mean test duration (in s) was calculated.

The modified Schulte table (i.e. SchulteGorbov table (Mashin, 2006)) estimates fourfoldswitching of attention according to two different colours and two different sequence orders. In the middle of the screen there appeared a square table which contained random red numbers from 1 to 25 and black numbers from 1 to 24 . The participant was asked to mark red numbers in ascending order and black numbers in descending order as fast and as accurately as possible. Besides, every time they had to switch the colour and order of numbers in the following sequence: $1-$ a red number, $24-$ a black number, 2 - a red number, 23 - a black number, etc. The maximum allowed task duration was 5 minutes. Test duration (in s) was calculated. 
Statistical analysis. The data were tested for normal distribution using the KolmogorovSmirnov test. To compare differences between men and women, $t$ tests for independent samples were used for data with a normal distribution (height, weight, body mass index and BSA), and the Mann-Whitney $U$ test was used for age, which was not normally distributed. Repeated-measures analysis of variance (ANOVA) was used to analyse the effects of cold stress on body temperatures, metabolic responses and cognitive performance variables, and the means were compared between men and women using a univariate ANOVA. The data are reported as mean (), standard deviation $(S D)$ and $95 \%$ confidence interval $(95 \% C I)$. The partial eta squared $\left(h_{p}{ }^{2}\right)$ was estimated as a measure of cold stress effect size. The level of significance was set at $p<.05$. If a significant effect was found, the statistical power $(S P$, in \%) was estimated. All statistical analysis was performed using SPSS v.21.0 (IBM Corp., Armonk, NY, USA).

\section{RESULTS}

Physical characteristics. The baseline characteristics of the participants are described in Table 1. Height, weight and BSA were higher in men than in women $(p<.05)$, whereas age and BMI did not differ between genders.

Effect of body cooling on body temperature variables. Table 2 summarizes the body temperatures variables for men and women before and after

\begin{tabular}{|l|c|c|c|c|c|}
\hline \multirow{2}{*}{$\begin{array}{c}\text { Physical } \\
\text { characteristics of } \\
\text { the participants }\end{array}$} & \multicolumn{2}{|c|}{$\begin{array}{c}\text { Men } \\
(\mathbf{n = 1 3})\end{array}$} & \multicolumn{2}{c|}{$\begin{array}{c}\text { Women } \\
(\mathbf{n = 1 3})\end{array}$} & \\
\cline { 2 - 6 } & $\pm \boldsymbol{S D}$ & $\mathbf{9 5 \%} \boldsymbol{C I}$ & $\pm \boldsymbol{S D}$ & $\mathbf{9 5 \%} \boldsymbol{C I}$ & $* \boldsymbol{p}$ value \\
\hline Age (years) & $20.6 \pm 1.1$ & $19.9-21.3$ & $20.8 \pm 1.6$ & $19.9-21.8$ & .678 \\
\hline Height $(\mathrm{cm})$ & $182.6 \pm 6.5$ & $178.7-186.6$ & $170.7 \pm 7.2$ & $166.3-175.1$ & .000 \\
\hline Mass $(\mathrm{kg})$ & $75.4 \pm 7.4$ & $70.9-79.9$ & $62.6 \pm 9.9$ & $56.7-68.6$ & .001 \\
\hline $\begin{array}{l}\text { Body mass index } \\
\left(\mathrm{kg} / \mathrm{m}^{2)}\right.\end{array}$ & $22.6 \pm 1.8$ & $21.5-23.6$ & $21.5 \pm 3.0$ & $19.7-23.3$ & .281 \\
\hline $\begin{array}{l}\text { Body surface area } \\
\left(\mathrm{m}^{2)}\right.\end{array}$ & $1.95 \pm 0.12$ & $1.88-2.02$ & $1.7 \pm 0.2$ & $1.65-1.83$ & .001 \\
\hline
\end{tabular}

Table 1. Physical characteristics of the participants

Note. - mean; $S D$ - standard deviation; $C I$ - confidence interval; ${ }^{*} p$ - men compared to women.

Table 2. Body temperature variables before and after body cooling

\begin{tabular}{|c|c|c|c|c|c|}
\hline \multirow{2}{*}{ Body temperature variables } & \multicolumn{2}{|c|}{ Men } & \multicolumn{2}{|c|}{ Women } & \multirow[b]{2}{*}{${ }^{*} p$ value } \\
\hline & $\pm S \boldsymbol{D}$ & $95 \% C I$ & $\pm S D$ & $95 \% C I$ & \\
\hline $\begin{array}{l}\text { Rectal temperature } \\
\text { Before cooling }\left({ }^{\circ} \mathrm{C}\right) \\
\text { After cooling }\left({ }^{\circ} \mathrm{C}\right) \\
\mathrm{y}_{p}{ }^{2} \\
\S p \text { value }\end{array}$ & $\begin{array}{c}37.0 \pm 0.2 \\
35.9 \pm 0.5 \\
.816 \\
.000\end{array}$ & $\begin{array}{l}36.8-37.1 \\
35.6-36.2\end{array}$ & $\begin{array}{c}36.9 \pm 0.2 \\
35.9 \pm 0.6 \\
.748 \\
.000\end{array}$ & $\begin{array}{l}36.8-37.0 \\
35.5-36.2\end{array}$ & $\begin{array}{c}.346 \\
1.000\end{array}$ \\
\hline $\begin{array}{l}\text { Skin temperature } \\
\text { Before cooling }\left({ }^{\circ} \mathrm{C}\right) \\
\text { After cooling }\left({ }^{\circ} \mathrm{C}\right) \\
\text { yp2 } \\
\text { §p value }\end{array}$ & $\begin{array}{c}32.6 \pm 0.7 \\
18.7 \pm 1.3 \\
.989 \\
.000\end{array}$ & $\begin{array}{l}32.2-33.3 \\
17.8-19.3\end{array}$ & $\begin{array}{c}32.2 \pm 0.5 \\
20.5 \pm 3.4 \\
.930 \\
.000\end{array}$ & $\begin{array}{l}31.9-32.4 \\
18.6-22.9\end{array}$ & $\begin{array}{l}.062 \\
.096\end{array}$ \\
\hline $\begin{array}{l}\text { Rectal-skin temperature } \\
\text { gradient } \\
\text { Before cooling }\left({ }^{\circ} \mathrm{C}\right) \\
\text { After cooling }\left({ }^{\circ} \mathrm{C}\right) \\
\text { yp2 } \\
\text { \$p value }\end{array}$ & $\begin{array}{c}4.3 \pm 0.8 \\
17.2 \pm 1.4 \\
.990 \\
.000\end{array}$ & $\begin{array}{c}3.8-4.8 \\
16.6-18.2\end{array}$ & $\begin{array}{c}4.7 \pm 0.4 \\
15.8 \pm 3.4 \\
.914 \\
.000\end{array}$ & $\begin{array}{c}4.5-5.0 \\
12.9-17.3\end{array}$ & $\begin{array}{l}.107 \\
.101\end{array}$ \\
\hline $\begin{array}{l}\text { Body temperature } \\
\text { Before cooling }\left({ }^{\circ} \mathrm{C}\right) \\
\text { After cooling }\left({ }^{\circ} \mathrm{C}\right) \\
\text { yp2 } \\
\text { §p value }\end{array}$ & $\begin{array}{c}35.4 \pm 0.3 \\
29.9 \pm 0.6 \\
.984 \\
.000\end{array}$ & $\begin{array}{l}35.2-35.7 \\
29.5-30.2\end{array}$ & $\begin{array}{c}35.2 \pm 0.2 \\
30.5 \pm 1.2 \\
.943 \\
.000\end{array}$ & $\begin{array}{c}35.1-35.43 \\
29.8-31.4\end{array}$ & $\begin{array}{l}.053 \\
.118\end{array}$ \\
\hline
\end{tabular}

Note. - mean; $S D$ - standard deviation; $C I$ - confidence interval; $h_{p}{ }^{2}$ - partial eta squared; * $p$ - men compared to women; $\S p-$ before cooling compared to after cooling. 
Table 3. Oxygen consumption ( $\left.\mathrm{VO}_{2}\right)$ and metabolic heat production (MHP) before and after body cooling

\begin{tabular}{|c|c|c|c|c|c|}
\hline \multirow{2}{*}{ Variables } & \multicolumn{2}{|c|}{ Men } & \multicolumn{2}{|c|}{ Women } & \multirow[b]{2}{*}{${ }^{*} p$ value } \\
\hline & $\pm S D$ & $95 \% C I$ & $\pm S D$ & $95 \% C I$ & \\
\hline \begin{tabular}{|l}
$\mathrm{VO}_{2}(\mathrm{ml} / \mathrm{min})$ \\
Before cooling \\
During cooling \\
$h_{p}{ }^{2}$ \\
$\S p$ value \\
\end{tabular} & $\begin{array}{c}164.7 \pm 56.2 \\
924.5 \pm 215.2 \\
.935 \\
.000\end{array}$ & $\begin{array}{c}124.4-195.2 \\
785.8-1070.9\end{array}$ & $\begin{array}{c}156.9 \pm 42.4 \\
542.1 \pm 150.2 \\
.899 \\
.000\end{array}$ & $\begin{array}{l}126.5-176.4 \\
452.6-648.0\end{array}$ & $\begin{array}{l}.691 \\
.000\end{array}$ \\
\hline $\begin{array}{c}\mathrm{VO}_{2}(\mathrm{ml} / \mathrm{min} / \mathrm{kg}) \\
\text { Before cooling } \\
\text { During cooling } \\
h_{p}{ }^{2} \\
\S p \text { value }\end{array}$ & $\begin{array}{c}2.2 \pm 0.7 \\
12.4 \pm 3.3 \\
.919 \\
.000\end{array}$ & $\begin{array}{c}1.7-2.6 \\
10.3-14.6\end{array}$ & $\begin{array}{c}2.6 \pm 0.8 \\
8.9 \pm 3.3 \\
.847 \\
.000\end{array}$ & $\begin{array}{c}2.0-3.0 \\
7.1-11.3\end{array}$ & $\begin{array}{l}.226 \\
.013\end{array}$ \\
\hline $\begin{array}{c}\mathrm{VO}_{2}\left(\mathrm{ml} / \mathrm{min} / \mathrm{m}^{2}\right) \\
\text { Before cooling } \\
\text { During cooling } \\
h_{p}{ }^{2} \\
\S p \text { value }\end{array}$ & $\begin{array}{c}84.4 \pm 27.2 \\
475.6 \pm 113.4 \\
.931 \\
.000\end{array}$ & $\begin{array}{c}64.8-97.7 \\
400.1-550.5\end{array}$ & $\begin{array}{c}90.8 \pm 25.2 \\
316.2 \pm 101.7 \\
.875 \\
.000\end{array}$ & $\begin{array}{c}72.6-104.2 \\
257.2-388.4\end{array}$ & $\begin{array}{l}.542 \\
.001\end{array}$ \\
\hline \begin{tabular}{|l} 
MHP $(\mathrm{W})$ \\
Before cooling \\
During cooling \\
$h_{p}{ }^{2}$ \\
$\S p$ value
\end{tabular} & $\begin{array}{c}58.2 \pm 20.3 \\
318.2 \pm 74.4 \\
.934 \\
.000\end{array}$ & $\begin{array}{c}43.6-69.1 \\
270.0-368.7\end{array}$ & $\begin{array}{c}55.4 \pm 14.8 \\
188.0 \pm 51.8 \\
.899 \\
.000\end{array}$ & $\begin{array}{c}44.8-62.2 \\
157.0-224.5\end{array}$ & $\begin{array}{l}.696 \\
.000\end{array}$ \\
\hline MHP (W/kg) & & & & & \\
\hline $\begin{array}{l}\text { Before cooling } \\
\text { During cooling } \\
h_{p}{ }^{2} \\
\S p \text { value }\end{array}$ & $\begin{array}{c}0.77 \pm 0.25 \\
4.28 \pm 1.15 \\
.915 \\
.000\end{array}$ & $\begin{array}{l}0.59-0.90 \\
3.52-5.01\end{array}$ & $\begin{array}{c}0.90 \pm 0.27 \\
3.10 \pm 1.15 \\
.846 \\
.000\end{array}$ & $\begin{array}{l}0.71-1.06 \\
2.45-3.92\end{array}$ & $\begin{array}{l}.217 \\
.016\end{array}$ \\
\hline \begin{tabular}{|l} 
MHP $\left(\mathrm{W} / \mathrm{m}^{2}\right)$ \\
Before cooling \\
During cooling \\
$h_{p}^{2}$ \\
$\S p$ value
\end{tabular} & $\begin{array}{c}29.8 \pm 9.8 \\
163.8 \pm 39.7 \\
.928 \\
.000\end{array}$ & $\begin{array}{c}22.8-34.5 \\
137.2-189.9\end{array}$ & $\begin{array}{c}32.1 \pm 8.8 \\
109.7 \pm 35.2 \\
.874 \\
.000\end{array}$ & $\begin{array}{c}25.7-36.7 \\
89.2-134.7\end{array}$ & $\begin{array}{l}.539 \\
.001\end{array}$ \\
\hline
\end{tabular}

Note. - mean; $S D$ - standard deviation; $C I$ - confidence interval; $h_{p}{ }^{2}$ - partial eta squared; ${ }^{*} p$ - men compared to women; $\S p-$ before cooling compared to after cooling.

body. Passive cooling time did not differ between genders $(132.2 \pm 43.4 \mathrm{~min}$ for men and $140.6 \pm$ 41.5 min for women). $\mathrm{T}_{\mathrm{RE}}, \mathrm{T}_{\mathrm{SK}}$, and $\mathrm{T}_{\mathrm{B}}$ decreased $(p<.05, S P>99 \%)$, and $\mathrm{T}_{\mathrm{RE}}-\mathrm{T}_{\mathrm{SK}}$ increased $(p<.05$, $S P>99 \%$ ) after cold exposure for both genders. Body temperature variables did not differ between men and women.

Effect of body cooling on pulmonary gas exchange variables. Table 3 summarizes the $\mathrm{VO}_{2}$ and MHP variables for men and women before and after body cooling. Baseline $\mathrm{VO}_{2}$ and MHP did not differ between men and women. Cold-water immersion increased the total and normalized $\mathrm{VO}_{2 \text { and }}$ MHP in both genders ( $\left.p<.05, S P>99 \%\right)$. The $\mathrm{VO}_{2}$ and MHP ( $p<.05$, total, $S P>99 \%$; normalized against weight, $S P>70 \%$; normalized against BSA, $S P>95 \%$ ) during cold exposure were higher in men than in women. Cold water immersion induced increase of MHP corresponded high intensity shivering in men ( 5.96, SD 2.28, 95\% CI $4.61-7.69)$ and moderate intensity shivering in women ( $3.59, S D 0.79,95 \%$ CI 3.32 - 4.16). A significantly greater increase in shivering intensity was observed in men then in women during cold exposure $(p<.05, S P>90 \%)$.

Effect of body cooling on cognitive performance. Values representing performance in attention tasks for men and women are presented in Table 4. Body cooling significantly increased the duration of Schulte table task performance for both genders ( $p<0.05, S P>55 \%$ for men and $S P>90 \%$ for women). In men, body cooling significantly increased the duration of Schulte-Gorbov table performance ( $p<.05, S P>50 \%$ ), whereas cold did not affect task duration in women. 
Table 4. Attention task performance before and after cooling

\begin{tabular}{|c|c|c|c|c|c|}
\hline \multirow{2}{*}{ Variables } & \multicolumn{2}{|c|}{ Men } & \multicolumn{2}{|c|}{ Women } & \multirow[b]{2}{*}{ * $p$ value } \\
\hline & $\pm S D$ & $95 \% C I$ & $\pm S D$ & $95 \% C I$ & \\
\hline $\begin{array}{l}\text { Schulte table (s) } \\
\text { Before cooling } \\
\text { After cooling } \\
h_{p}{ }^{2} \\
\S p \text { value } \\
\end{array}$ & $\begin{array}{c}188.8 \pm 27.8 \\
203.4 \pm 29.5 \\
.318 \\
.036\end{array}$ & $\begin{array}{l}170.0-206.9 \\
182.9-221.6\end{array}$ & $\begin{array}{c}176.0 \pm 38.4 \\
195.8 \pm 38.9 \\
.549 \\
.002\end{array}$ & $\begin{array}{l}148.9-191.3 \\
167.8-15.5\end{array}$ & $\begin{array}{l}.342 \\
.579\end{array}$ \\
\hline $\begin{array}{c}\text { Schulte-Gorbov table (s) } \\
\text { Before cooling } \\
\text { After cooling } \\
h_{p}{ }^{2} \\
\S p \text { value }\end{array}$ & $\begin{array}{c}168.8 \pm 36.5 \\
186.8 \pm 47.3 \\
.284 \\
.049\end{array}$ & $\begin{array}{l}146.4-194.3 \\
157.1-219.4\end{array}$ & $\begin{array}{c}167.8 \pm 43.2 \\
175.9 \pm 46.9 \\
.215 \\
.095\end{array}$ & $\begin{array}{l}136.8-190.1 \\
142.5-202.8\end{array}$ & $\begin{array}{l}.950 \\
.562\end{array}$ \\
\hline
\end{tabular}

Note. - mean; $S D$ - standard deviation; $C I$ - confidence interval; $h_{p}{ }^{2}-$ partial eta squared; $* p-$ men compared to women; $\$ p-$ before cooling compared to after cooling.

\section{DISCUSSION}

The main aim of this study was to compare if whole body cooling induced any gender-specific response in attention stability task performance due to the differences of catecholamine-induced metabolic heat production between men and women. As expected, men exhibited greater whole body cooling induced MHP and shivering thermogenesis than women. Besides, the results of this study have shown that greater mental manipulation requiring Schulte-Gorbov table was affected in men but not in women, whereas less cognitively demanding Schulte table performance was adversely affected in both genders.

$$
\text { Whole body cooling induced }
$$
thermoregulatory response in men and women. The origin of thermoregulation in noncold-adapted humans involves metabolic (an increase in heat production), hypothermic (a reduction in core temperature) and insulative (a reduction in $\mathrm{T}_{\mathrm{SK}}$ relative to core temperature) (Brazaitis et al., 2014a, b). In accordance with a previous study (McArdle, Toner, Magel, Spina, \& Pandolf, 1992; Solianik et al., 2014b), on exposure to cold water, both men and women exhibited an insulative response (an increase in $\mathrm{T}_{\mathrm{RE}}-\mathrm{T}_{\mathrm{SK}}$ gradient), a metabolic response (an increase in MHP and shivering $\left.\left(\mathrm{VO}_{2}\right)\right)$, and a hypothermic response (a decrease in $\mathrm{T}_{\mathrm{RE}}$ ). As expected and in accordance with our previous study (Solianik et al., 2014b) we have observed that MHP and shivering were significantly greater in men than in women. It is well established that catecholamines cause a rise in MHP, including shivering (Banet et al., 1978; Maggs et al., 1994); specifically increased circulating epinephrine in men compared to women (Maggs et al., 1994; Solianik et al., 2014b; Wagner et al., 1987).

Whole body cooling induced attention stability response in men and women. We chose to assess attention stability using two tasks of different task complexity, such as Schulte table (less cognitively demanding task) and Schulte-Gorbov table (more cognitively demanding task). As previously mentioned cold-induced catecholamines increase particularly deteriorates tests involving complex attentional functions (Hyafil et al., 2009). Thus in a recent study observed greater metabolic response in men then in women indicates greater epinephrine response in men (Maggs et al., 1994; Solianik et al., 2014 b; Wagner et al., 1987), which deteriorates Schulte-Gorbov task performance in men, but not in women. The arousal hypothesis suggests that a slight decline in core temperature leads to improved performance, whereas with continued, prolonged and more severe cooling performance is degraded (Enander, 1987). It can be suggested that especially complex cognitive tasks are susceptible to the arousal caused by the cold exposure (Giesbrecht et al., 1993; Mäkinen et al., 2006; Mäkinen, 2007; Palinkas et al., 2005), and follows 'inverted U-shaped' pattern (Arnsten, 2009; Lupien, McEwen, Gunnar, \& Heim, 2007; Shansky \& Lipps, 2013). Thus it can be expected that women blunted Schulte-Gorbov performance change was due to parallel move ahead of the inverted $U$ shaped curve; by contrast, in men greater catecholamines response moved further ahead and caused performance deterioration. 
In contrast to more cognitively demanding Schulte-Gorbov table, less cognitively demanding Schulte test duration increased in men and women. The distraction hypothesis suggests that the discomfort caused by cold produces a shift of attention from the primary task and leading to performance decrement (Mäkinen, 2007; Teichner, 1958), such as longer response time (Mäkinen, 2007). It is suggested that especially simple cognitive tasks are susceptible to the distraction caused by the cold exposure (Giesbrecht et al., 1993; Mäkinen et al., 2006; Mäkinen, 2007). Off note, it is suggested that cold-induced discomfort may be a distraction factor reducing the performance of task (Mäkinen, 2007). In our previous study (Solianik et al., 2014b) we did not observe any gender differences in thermal sensation and comfort perception, which is in line with our resent findings indicating similar Schulte test duration increase in men and women.

\section{CONCLUSIONS}

Whole body cooling induced stress had similar influence on simple attention stability task in men and women, whereas more complex attention stability task was adversely affected only in men. This greater men's decrement of more complex cognitive task performance can be associated with men's greater catecholamine conveyed metabolic heat production, including shivering, compared to women. This is the first study to find the evidence supporting the idea of gender-specific and taskdependent attention stability response after whole body cooling.

\section{REFERENCES}

Arnsten, A. F. (2009). Stress signalling pathways that impair prefrontal cortex structure and function. Nature Reviews. Neuroscience, 10(6), 410-422. doi: 10.1038/ nrn2648

Banet, M., Hensel, H., \& Liebermann, H. (1978). The central control of shivering and non-shivering thermogenesis in the rat. Journal of Physiology, 283, 569-584.

Berneckè, V., Eimantas, N., Paulauskas, H., Skaisgiryte, B., Kudrevičius, J., \& Brazaitis, M. (2012). Assessment of the reliability of cognitive (attention and memory) tests. Education. Physical Training. Sport, 3(86), 18-25.

Brazaitis, M., Eimantas, N., Daniuseviciute, L., Baranauskiene, N., Skrodeniene, E., \& Skurvydas, A. (2014a). Time course of physiological and psychological responses in humans during a 20-day severe-coldacclimation programme. PLoS ONE, 9(4), e94698. doi: 10.1371/journal.pone.0094698

Brazaitis, M., Eimantas, N., Daniuseviciute, L., Mickeviciene, D., Steponaviciute, R., \& Skurvydas, A. (2014b). Two strategies for response to $14^{\circ} \mathrm{c}$ cold-water immersion: Is there a difference in the response of motor, cognitive, immune and stress markers? PLoS One, 9(9), e109020. doi: 10.1371/journal.pone.0109020

Burton, A. C. (1935). Human calorimetry: II. The average temperature of the tissues of the body. Journal of Nutrition, 9(3), 261-280.

Coleshaw, S. R. K, van Someren, R. N. M., Wolff, A. H., Davis, H. M., \& Keatinge, W. R. (1983). Impaired memory registration and speed of reasoning caused by low body temperature. Journal of Applied Physiology: Respiratory, Environmental and Exercise Physiology, 55(1 Pt 1), 27-31.

Enander, A. (1987). Effects of moderate cold on performance of psychomotor and cognitive tasks, Ergonomics, 30(10), 1431-1445.
Giesbrecht, G. G., Arnett, J. L., Vela, E., \& Bristow, G. K. (1993). Effect of task complexity on mental performance during immersion hypothermia. Aviation, Space, and Environmental Medicine, 64(3 Pt 1), 206-211.

Gordeev, S. A. (2008). Cognitive functions and the state of nonspecific brain systems in panic disorders. Neuroscience and Behavioral Physiology, 38(7), 707714. doi: 10.1007/s11055-008-9036-z

Haman, F. (2006). Shivering in the cold: from mechanisms of fuel selection to survival. Journal of Applied Physiology, 100(5), 1702-1708.

Hyafil, A., Summerfield, C., \& Koechlin, E. (2009). Two mechanisms for task switching in the prefrontal cortex. Journal of Neuroscience, 29(16), 5135-5142. doi: 10.1523/JNEUROSCI.2828-08.2009.

Lockhart, T. L., Jamieson, C. P., Steinman, A. M., \& Giesbrecht, G. G. (2005). Life jacket design affects dorsal head and chest exposure, core cooling, and cognition in 10 degrees C water. Aviation, Space, and Environmental Medicine, 76(10), 954-962.

Lupien, S. J., McEwen, B. S., Gunnar, M. R., \& Heim, C. (2009). Effects of stress throughout the lifespan on the brain, behaviour and cognition. Nature Reviews. Neuroscience, 10(6), 434-445. doi: 10.1038/nrn2639

Maggs, D. G, Gallen, I. W., Fone, K., \& Macdonald, I. A. (1994). Metabolic heat production and cardiovascular responses to an incremental intravenous infusion of adrenaline in healthy subjects. Clinical Autonomic Research, 4(3), 131-136.

Mäkinen, T. M. (2007). Human cold exposure, adaptation, and performance in high latitude environments. American Journal of Human Biology, 19(2), 155-164.

Mäkinen, T. M., Palinkas, L. A., Reeves, D. L., Pääkkönen, T., Rintamäki, H., Leppäluoto, J., \& Hassi, J. (2006). Effect of repeated exposures to cold on cognitive performance in humans. Physiology \& Behavior, 87(1), $166-176$. 
Mashin, V. A. (2006). The relationship of the slope of the heart rate graph regression with linear and nonlinear heart rate dynamics in stationary short-time series. Biophysics, 51(3), 471-479.

McArdle, W. D., Toner, M. M., Magel, J. R., Spina, R. J., Pandolf, K. B. (1992). Thermal responses of men and women during cold-water immersion: Influence of exercise intensity. European Journal of Applied Physiology Occupational Physiology, 65(3), 265-270.

Mermier, C. M., Schneider, S. M., Gurney, A. B., Weingart, H. M., \& Wilmerding, M. V. (2006). Preliminary results: Effect of whole-body cooling in patients with myasthenia gravis. Medicine and Science in Sports and Exercise, 38(1), 13-20.

Muller, M. D., Gunstad, J., Alosco, M. L., Miller, L. A., Updegraff, J., Spitznagel, M. B., \& Glickman, E. (2012). Acute cold exposure and cognitive function: Evidence for sustained impairment. Ergonomics, 55(7), 792-798. doi: 10.1080/00140139.2012.66549

Palinkas, L.A. (2001). Mental and cognitive performance in the cold. International Journal of Circumpolar Health, 60(3), 430-439.

Péronnet, F., \& Massicotte, D. (1991). Table of nonprotein respiratory quotient: An update. Canadian Journal of Sport Sciences, 16(1), 23-29.

Prokopenko, S. V., Mozheyko, E. Y., Petrova, M. M., Koryagina, T. D., Kaskaeva, D. S., Chernykh, T. V., ... Bezdenezhnih, A. F. (2013). Correction of post-stroke cognitive impairments using computer programs. Journal of the Neurological Sciences, 325(1), 148-153. doi: 10.1016/j.jns.2012.12.024

Shansky, R. M., \& Lipps, J. (2013). Stress-induced cognitive dysfunction: Hormone-neurotransmitter interactions in the prefrontal cortex. Frontiers in Human Neuroscience, 7(123), 1-6. doi: 10.3389/ fnhum.2013.00123

Solianik, R., Skurvydas, A., Mickevičienè, D., Brazaitis, M. (2014a). Intermittent whole-body cold immersion induces similar thermal stress but different motor and cognitive responses between males and females. Cryobiology, 69(2), 323-332. doi: 10.1016/j. cryobiol.2014.08.007

Solianik, R., Skurvydas, A., Vitkauskienè, A., \& Brazaitis, M. (2014b). Gender-specific cold responses induce a similar body-cooling rate but different neuroendocrine and immune responses. Cryobiology 69(1), 26-33. doi: 10.1016/j.cryobiol.2014.04.015

Teichner, W. H. (1958). Reaction time in the cold. Journal of Applied Psychology, 42, 54-59.

Tikuisis, P., Jacobs, I., Moroz, D., Vallerand, A. L., \& Martineau, L. (2000). Comparison of thermoregulatory responses between men and women immersed in cold water. Journal of Applied Physiology, 89(4), 1403-1411.

Wagner, J. A., Horvath, S. M., Kitagawa, K., \& Bolduan, N. W. (1987). Comparisons of blood and urinary responses to cold exposures in young and older men and women. The Journals of Gerontology Series A: Biological Sciences and Medical Sciences, 42(2), 173-179. 